\title{
FEMINICÍDIO, SISTEMA JURÍDICO DE PROTEÇÃO À MULHER E NORMATIVIDADE: UMA ANÁLISE SEGUNDO HART E RAZ1
}

Lucas Prado Kizan ${ }^{2}$

Resumo: O Brasil é um campo fértil de normas e leis, que surgem a todo instante. Porém, surge a duvida se todas as normas brasileiras são compatíveis entre si. Este é o questionamento que o presente trabalho visa responder. $\mathrm{O}$ feminicídio é utilizado como objeto de estudo. Para tanto serão abordados o movimento feminista e a legislação protetiva da mulher. Ao final são instrumentalizadas as teorias de Herbert Hart e Joseph Raz, além de um análise jurídico-penal, para se chegar a uma conclusão quanto a posição normativa do crime de feminicídio, na legislação brasileira.

Palavras chave: Feminicídio; Normatividade; Sistemas jurídicos; proteção a mulher; feminismo.

\section{FEMINICIDE, LEGAL SYSTEM OF PROTECTION FOR WOMEN AND NORMATIVITY: AN ANALYSIS ACCORDING TO HART AND RAZ}

\begin{abstract}
Brazil is a fertile field of norms and laws, which arise at every moment. But are all the rules that make up the Brazilian legal system compatible with each other? This is the question that the present paper aims to answer. Femicide is used as an object of study. To this end, the feminist movement and the protective legislation of women will be addressed. In the end, the theories of Herbert Hart and Joseph Raz are instrumentalized to arrive at a conclusion on the theory of law. Criminal-legal analysis is also done.
\end{abstract}

Keywords: Feminicide, Normativity, Legal systems.

\footnotetext{
${ }^{1}$ Trabalho apresentado ao Prof. Dr. Jean Carlos Dias, como componente parcial para obtenção de créditos da disciplina teoria do pensamento jurídico contemporâneo, do Programa de pós-graduação em Direito do CESUPA.

2 Mestrando no PPGD-CESUPA; especialista em direito digital e compliance pela faculdade Damásio; especialista em ciências criminais pela UNAMA; bacharel em direito na faculdade ideal; professor da disciplina direito das organizações, na faculdade Pan Amazônica; coordenador da linha de pesquisa em direito digital da liga acadêmica de direito do Pará; advogado, membro da comissão de segurança pública da OAB/PA e consultor da comissão de direito digital e compliance, da OAB/SP.
} 


\section{INTRODUÇÃO}

O Brasil é um país notadamente burocrático, com um sistema jurídico inflado e confuso.

Burocracia, segundo o dicionário online Michaelis, é o "Sistema de administração pública por meio de um conjunto de funcionários lotados em ministérios, secretarias e órgãos, sujeitos a regulamento, hierarquia e rotina". Regulamentação se faz por meio de normas e é o excesso delas que constitui o pilar do problema objeto deste trabalho. Segundo estudo realizado pelo Instituto Brasileiro de Planejamento e Tributação - IBPT (2014), desde a promulgação da Constituição Federal de 1988, já foram editadas 5.471 .980 (cinco milhões, quatrocentos e setenta e um mil e novecentos e oitenta) normas ${ }^{3}$.

No maio desse leviatã normativo, será que todas essas milhões de normas se justificam e se sustentam quando analisadas a partir de critérios propostos por teóricos do Direito? Pretende-se responder este questionamento a partir do estudo do tipo penal do feminicídio como componente da legislação protetiva da mulher. O referido crime será colocado em questão e discutido segundo as teorias desenvolvidas por Herbert Hart e Joseph Raz.

Este trabalho em momento algum pretende esgotar a explanação dos pensamentos de ambos os autores, mas somente fazer um recorte de certos pontos, tanto para tornar uma leitura mais ágil quanto para incentivar o leitor a estudar diretamente estes dois expoentes da teoria do Direito.

O primeiro capítulo aborda, de forma sucinta, a teoria desenvolvida por Herbert Hart; o segundo capítulo trará, também de forma breve, o entendimento de Joseph Raz; no terceiro capítulo será estudado superficialmente o movimento do feminismo, com especial atenção à Lei Maria da Penha e ao crime de Feminicídio. Ao final são expostas as conclusões do trabalho, em uma inicial análise jurídico-penal, e em seguida se encerra com as visões de Hart e Raz sobre a legislação de proteção a mulher e o crime de feminicídio.

\section{A TEORIA DE HERBERT HART}

\subsection{Normatividade e norma de reconhecimento}

A noção de normatividade perpassa pela obediência à norma, vale dizer, o dever de obedecer certa norma e o motivo que leva um individuo a se submeter a determinada obrigação juridicamente válida é o cerne da questão abordada pelo estudo da normatividade.

Herbert Hart, professor de Filosofia do Direito na Universidade de Oxford, era conhecido por ser um liberal defensor do Estado democrático, da liberdade sexual, defensor do aborto e contra a pena de morte (STALZ, 2007).

Para falar da normatividade em Hart, é necessário estabelecer que, para este autor, ao se tratar de uma sociedade complexa, há normas primárias e secundárias. As normas primárias

3 Isto é, até a data de 30 de setembro de 2016, que compreende o período alcançado pelo referido estudo. 
são aquelas baseadas em ameaças, vale dizer, com uma punição vinculado ao seu descumprimento, para garantir coercitividade normativa. As normas primárias são de comportamento, que obrigam ou proíbem algo (HART, 2001).

Já as secundárias são normas de poder e validade. Criam outras normas e organizam a estrutura normativa. São normas sobre normas. Determinam critérios de criação de normas (como o processo legislativo) e determina mecanismos de aplicação das normas (como códigos processuais, por exemplo).

Hart também estabelece separação entre Direito e moral, a partir de uma diferenciação quanto a:

Importância, onde as normas morais já não possuem relevância para determinada sociedade simplesmente deixa de ser uma regra, no passo em que regras jurídicas podem perder a importância e mesmo assim continuarem vigorando, pois estas últimas obedecem um sistema próprio de criação e extinção;

imunidade à alteração deliberada, se trata de uma separação mais nítida. Aqui temos a possibilidade constante de criação e extinção de normas jurídicas, que podem surgir e sumir a todo instante, respeitando seu processo legislativo, no passo em que regras morais não podem simplesmente nascer, elas dependem de uma mudança de comportamento social.

Caráter voluntário dos delitos morais, na esfera moral uma conduta contraria a normatividade possui uma maior abertura para ser justificada, seja pela ausência de previsibilidade do resultado (culpa) seja por ausência de intenção (dolo), enquanto que uma regra jurídica está inserida em um espaço menor para a possibilidade de justificativa, neste campo a responsabilização pode ser objetiva, independente de culpa ou dolo;

Pressão onde nas regras morais são dotadas de uma sanção mais interna do sujeito, em caráter mais psicológico, o tom de reprovação social que pode vir a ocorrer após o descumprimento da regra, porém, a contrariedade a norma jurídica gera está atrelada à uma ameaça de sanção pela inobservância.

Para Hart, a obediência não é um mero ato de receber uma ordem e agir como tal, pois o destinatário da ordem pode fazer o determinado mesmo que não haja um direcionamento especifico neste sentido, que é o comportamento de hábito. Por outro lado, uma obediência pautada apenas na ameaça de castigo, sem constituir hábito, não implica dizer que a desobediência será perpetuada.

Hart explica que, para a obediência à regra implica em continuidade da mesma, não importando quem esteja ocupando a figura do soberano, deve haver aceitação por parte da sociedade, ou seja, as pessoas devem reconhecer o aspecto externo da regra, que implica no alcance geral, é o que um observador externo vê; e o aspecto interno, que significa o julgamento interno que cada pessoa tem acerca do comportamento dos demais, tanto sobre o cumprimento da regra quanto sobre a contrariedade.

Fica claro que Hart não entende que a moral faça parte de um sistema jurídico. Ela o orbita, podendo inclusive, com o tempo, passar a guiar certos comportamentos, que em razão 
de sua continuidade, poderão a vir se tornar normas jurídicas, entretanto, em um primeiro momento, normas morais são tidas como externas ao conceito de sistema jurídico hartiano.

Para que haja validade no sistema jurídico complexo, composto por normas primárias e normas secundárias, proposto por Hart, há um ponto fundamental a ser observado, que é a norma de reconhecimento.

A norma de reconhecimento se refere à uma norma secundária, isto é, norma que confere poder a outras normas. Se refere a estrutura última de fundamento da existência de demais regras; é a aceitação social da regra, consubstanciada com a obediência e a identificação de justiça do objetivo da regra, conceito intimamente ligado com o aspecto interno da regra.

Norma de reconhecimento é a nascente do sistema jurídico de Herbert Hart, todas as demais dela derivam e se não obtiverem compatibilidade com ela, não podem ser consideradas normas jurídicas do sistema, por ausência de validade, que apenas a norma de reconhecimento é capaz de prover.

Para os efeitos deste estudo, podemos considerar nossa Constituição Federal como nossa norma de reconhecimento, para o sistema jurídico brasileiro, isto é, na visão de Herbert Hart.

\subsection{Sistemas jurídicos}

Para Hart sistema jurídico é o emaranhado de normas que surge a partir da norma de reconhecimento e que é compatível com os critérios de validade contidos nesta norma maior.

A resposta para os problemas a respeito do conceito de Direito, de Hart, é no sentido de que o comportamento social indica a aceitação de determinada norma no âmbito interno de uma sociedade. E que como as normas visam obrigar condutas, se tratam de normas sociais, logo o comportamento social incentiva a criação de uma norma, que será confirmada pela obediência, que por sua vez pode ser observada a partir da aceitação social daquele mandamento.

Por fim, a regra de reconhecimento é em si mesma, norma e fato social, simultaneamente. A validade jurídica é questão de fato (COLEMAN, 1991).

Então se denota que um sistema jurídico é um sistema social de criação, validação e obediência às normas.

\section{A TEORIA DE JOSEPH RAZ}

Joseph Raz é israelense, foi orientado em seu doutorado em Oxford por Hart e possui grande influência do autor inglês. Raz teceu críticas à teoria desenvolvida por seu professor e desenvolveu sua própria, na qual faremos agora um breve passeio.

Raz aponta falhas na teoria de Hart, inicialmente pela baixa complexidade do estudo desenvolvido por seu orientador. Enquanto Hart propôs que sociedades complexas possuem dois tipos de normas em seus sistemas jurídicos, Raz diz que Hart ignorou a 
existência de outros tipos de normas, e que mal interpretou a natureza da norma de reconhecimento.

Raz discorda de seu mentor a respeito da natureza de norma secundária, de conferência de poder, da norma de reconhecimento, mas sim entende se tratar de norma de conduta, que irá estabelecer o comportamento das autoridades estatais no julgamento das condutas sociais.

A teoria raziana sustenta que um sistema jurídico é uno, se trata de corpo único de normas e leis. Cada lei existente tem em sua lógica, em sua genética, os critérios de validade e identidade da norma de reconhecimento. Uma única lei de um sistema jurídico, que é destacada para um caso concreto, deve ser capaz de, ao ser observada, identificar a qual sistema jurídico pertence, justamente em razão do critério de identidade. Então uma lei pertence a um sistema jurídico a partir do momento em que se relaciona com demais leis do mesmo sistema, e que funcionam de forma una e coesa, e mesmo que uma lei deste fique em evidência, ela sozinha é capaz de apontar seu sistema jurídico originário.

Esta possibilidade de se destacar uma dentre várias leis de um sistema, e a partir dela reconhecer o sistema é chamada por Raz de princípio de individuação.

O autor não explica o princípio da individuação pois ele será diferente para cada sistema jurídico.

Segundo Jean Carlos Dias e Carla Peixoto (2017)

"Em geral, seriam dois os requisitos que servem como norte para os princípios de individuação: 1) os requisitos de orientação que apresentam os objetivos nos quais os princípios de individuação devem agir, ajudando a escolher o melhor grupo de princípios de individuação que passaram no teste dos requisitos de limitação, sendo, sobretudo, princípios de exclusão e 2) os requisitos de limitação, os quais especificam o que deve ser evitado, determinam e excluem certas sugestões impróprias dos possíveis grupos de princípios de individuação, sendo essencialmente princípios de exclusão. Logo, os princípios de individuação é que irão individuar as leis de determinado sistema jurídico (RAZ, 2012)."

Raz continua sua crítica ao dizer que não entende se tratar a norma de reconhecimento uma norma social, mas sim uma norma que impõe obrigação, e que "muitas regras não se destinam a um grupo específico, mas a uma subclasse particular do grupo (como regras para idosos etc.) ou a quem não faz parte do grupo (como estrangeiros)" (DIAS. PEREIRA, 2017.).

O sistema jurídico Hartiano é composto unicamente por leis, no passo em que Raz afirma que um sistema jurídico só o será se for complexo, e com isso afirma que há leis e normas no sistema jurídico, e que nem toda norma é lei.

A normatividade se encontra na interdependência conceitual das leis dentro de um mesmo sistema jurídico, então ao se falar em normatividade, o conceito de sistema jurídico surge, em vez de uma simples explicação sobre obediência à uma norma. Lei e sistema jurídico possuem sua definição e conceito interdependentes, pois uma lei só será reconhecida como tal a partir de sua relação interna com outras leis e normas do mesmo sistema. 
Raz, para determinar quais leis pertencem a um sistema jurídico e quais não, criou o conceito de enunciado fundamental (RAZ, 2012), que exprime que a relação de Direito entre sujeito e objeto ou entre sujeitos. Toda lei que contenha o mesmo enunciado fundamental, pertence ao mesmo sistema jurídico.

\section{O SISTEMA JURÍDICO DA PROTEÇÃO DA MULHER}

\subsection{Feminismo}

Após falar abstratamente dos conceitos de sistema jurídicos, iremos abordar concretamente a legislação protetiva a mulher no Brasil.

O Brasil é um país positivista, normatizado e institucionalizado, onde o Direito positivo faz as vias de regulação social.

Como já comentado, Hart assevera que a lei é uma norma social e que surge a partir do comportamento do povo.

Mobilizações sociais e lutas por direitos são instrumentos democráticos de influência popular para a regulamentação legislativa de certo aspecto ainda não tutelado (ou mal tutelado) pelo Estado.

O feminismo se trata de movimento social, com forte viés político, que objetiva o tratamento igualitário entre os gêneros masculino e feminino.

Muitas foram as conquistas dos movimentos feministas, cujas lutas remontam desde a revolução francesa, que marca o início da chamada primeira onda do movimento feminista, que basicamente lutava pelo direito de cidadania, principalmente aos de cunho político e educação (SILVA, 2008).

No Brasil os primeiros registros de reivindicações de direitos para mulheres são do século XIX, cuja primeira bandeira foi o do direito ao aprendizado da leitura e da escrita (SILVA, 2008). Mas foi no século XX que lutas feministas conseguiram suas maiores vitórias.

O direito ao voto veio na década de 1930; na década de 1960 houve alteração do código civil de 1916, que passou a permitir o trabalho fora de casa sem a necessária autorização marital outrora exigida.

A mulher só foi ser dotada de plena capacidade civil, no código civil de 2002, até então o sexo feminino era considerado parcialmente incapaz, devendo ter a anuência do marido, ou do pai, para a convalidação de atos praticados, como de uma compra e venda ou abertura de conta bancária, por exemplo.

É nítida a clarividente a situação de inferioridade social que a mulher vivia, e a evolução jurídica do sexo feminino deve aos movimentos feministas, que chamaram a atenção para uma causa legitima e necessária. 
A segunda onda do feminismo, que se iniciou nos Estados Unidos, entre as décadas de 1960 e 1970 e rompia com a inicial ideologia do movimento, que se pautava no liberalismo (SILVA, 2008). ${ }^{4}$

Simone de Beauvoir, principal expoente da segunda onda, defende em sua obra intitulada "segundo sexo" (1949) uma ideologia maniqueísta, na qual colocava a figura do homem como a responsável pela opressão feminina. Pregava uma ideia que emulava a luta de classes propagada por Karl Max, mas na visão de Beauvoir, se transmutava em luta de gêneros (SILVA, 2008).

Em uma visão de conflito, não se busca a igualdade, e sim a superioridade, e é exatamente este posicionamento que passa a ditar as pautas do feminismo nacional, e direcionar as bandeiras de lutas partidárias, que acabaram por culminar na sanção de leis que em vez de pregar pela constitucional isonomia, aplicam um tratamento desigual que, no lugar de nivelar uma existente desigualdade, acabou por inverter a desigualdade, porém agora em favor do sexo feminino. ${ }^{5}$

\subsection{Lei Maria da Penha}

Em 09 de junho de 1994 foi finalizada a Convenção Internacional para Prevenir, Punir e Erradicar a Violência contra a Mulher, sediada em Belém do Pará. Para promulgar a aludida convenção, foi editado o Decreto $\mathrm{n}^{\circ} 1.973$ de 1996, e como consequência, dez anos depois, em 2006 houve a edição da lei 11.340, a famosa "lei Maria da Penha". Tal lei foi o resultado de condenação do Estado brasileiro pela negligência da violência sofrida por Maria da Penha Maia Fernandes, que denunciou o descaso do poder público à Organização dos Estados Americanos - OEA.

\footnotetext{
4 Fala-se em uma terceira onda, que prega que a exclusão feminina possui diferentes recortes e por isso as mulheres devem ser subdivididas em grupos, para que as reivindicações sejam direcionadas, e assim o movimento feminista se subdividiu pela luta dos direitos das mulheres negras, das mulheres latinas, mulheres homossexuais, mulheres cristãs etc., e que estaríamos vivendo a quarta, mas para os fins deste trabalho, esta subdivisão é irrelevante para o recorte da pesquisa.

5 Lei 8.213/1991 - Tempo de contribuição e idade mínima da mulher para obter aposentadoria inferior ao do homem;

Lei 11.340/2006 - "lei Maria da Penha", prevê maior assistência em caso de violência no âmbito doméstico e familiar apenas quando a vítima é mulher (homens, crianças e idosos não possuem especial proteção em caso de violência doméstica e familiar);

Lei complementar 150/2015 - prevê rescisão do contrato de trabalho por culpa do empregador em caso de cometimento de violência apenas contra a mulher;

Decreto 5.948/2006 - prevê uma maior proteção e assistência à mulher vítima de tráfico de pessoas (um homem e uma mulher vítimas desse tipo de atividade terão assistência governamental diferentes, segundo esta norma);

Lei 13.239/2015 - prevê a oferta de cirurgia plástica para reparar sequelas decorrentes de violência contra a mulher (homens vítimas de sequelas físicas por conta de violência não possuem tal procedimento coberto pelo Estado);

Lei 13.778/2013 - prevê notificação compulsória da violência cometida contra a mulher;

Lei 11.977/2009 - Prioriza famílias cujas responsáveis são mulheres, para receber em caráter prioritário um imóvel pelo programa Minha casa minha vida” (Famílias que dependam do homem são preteridas);

Lei 11.489/2007 - institui o dia nacional da mobilização dos homens, pelo fim da violência contra as mulheres;

Lei 4.735/1964 - trata do serviço militar obrigatório aos homens e facultado às mulheres;

Constituição Federal de 1988 - isenta as mulheres de alistamento militar para exercício do direito ao voto;
} 
A lei Maria da Penha representou grande marco no ordenamento jurídico pátrio. Se firmou como legislação de gênero, que cria mecanismos especiais de proteção à vítima de violência doméstica e/ou familiar que seja do gênero feminino.

A Lei em comento não cria tipo penal. Se trata de política pública de proteção do gênero feminino, que amplia o conceito de agressão, não se restringindo mais o entendimento à apenas lesão corporal, mas também à violência moral, psicológica, sexual e econômica.

Outros mecanismos inovadores (e polémicos) oriundos desta lei são as medidas protetivas de urgência, o tratamento especial às vítimas e a vedação de substituição da pena privativa de liberdade por restritiva de direitos. Além da vinculação de incondicionalidade da ação penal pública para o processamento de crimes no contexto familiar e/ou doméstico, cujas vítimas sejam do gênero feminino.

É de conhecimento geral que o simples fato de instituir determinada norma proibitiva não implica dizer que o ato proibido será expurgado. Como exemplo, tivemos a experiência da criação dos crimes hediondos, que objetivava a diminuição da incidência dos delitos sob o conceito da hediondez, no entanto o que se observou foi justamente o contrário, o aumento na prática delituosa desses crimes. ${ }^{6}$

A Lei Maria da Penha seguiu caminho semelhante, mas não idêntico. Em pesquisa realizada pelo Instituto de Pesquisa Econômica Aplicada - IPEA, sobre a efetividade desta lei, concluiu-se que, dentro do espaço amostral e do período analisado, nas localidades em que há maior presença estatal, houve uma diminuição de $10 \%$ na taxa desses tipos de delitos. Porém, nas localidades em que o Estado é mais ausente, demonstrou-se aumento na prática criminosa.

\subsection{Feminicídio}

Sem sombra de dúvida, a Lei Maria da Penha teve uma grande importância para chamar a atenção da sociedade a respeito da violência contra a mulher. Diversas pesquisas, como a já citada do IPEA, indicam que as mulheres vítimas de assassinatos normalmente padecem em ambiente doméstico familiar (em cerca de $90 \%$ dos casos). Como forma de combater esse triste dado, e de complementar a política instituída pela lei 11.340, foi adicionado ao código penal, o crime de feminicídio, pela lei $n^{\circ} 13.104 / 2015$, que acrescenta o inciso VI ao art. 121 (homicídio) e o parágrafo $2^{\circ}$-A, que assim dispõe:

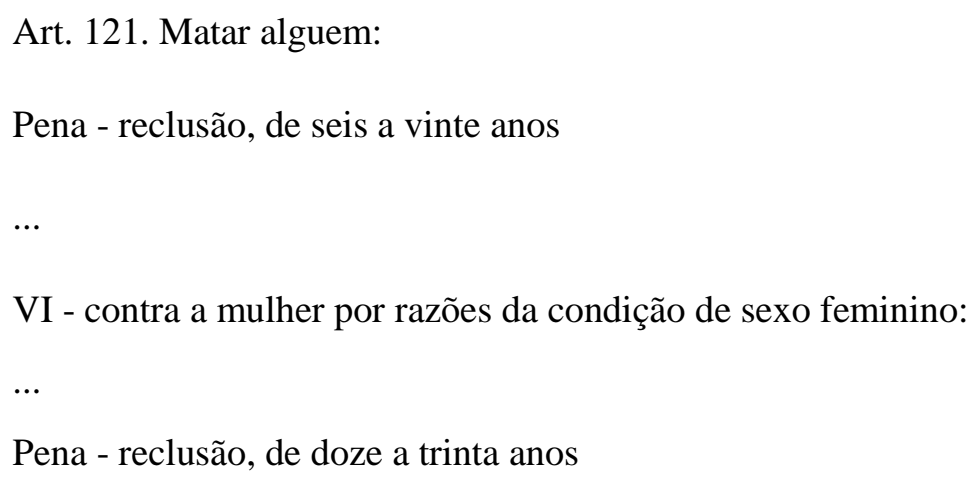

Pena - reclusão, de doze a trinta anos

6 Conforme os resultados da pesquisa realizada pelo Instituto Latino Americano das Nações Unidas para Prevenção do Delito e Tratamento do Delinqüente, em 2005. 
§ 2o-A Considera-se que há razões de condição de sexo feminino quando o crime envolve:

I - violência doméstica e familiar;

II - menosprezo ou discriminação à condição de mulher

Pode-se notar que o crime de feminicídio é uma qualificadora do crime de homicídio simples, que dobra a pena mínima e eleva a pena máxima ao teto de pena permitido em nossa legislação.

Outro fator importante a ser ressaltado é que há condicionante do polo passivo ser mulher, por condição do sexo feminino, diferente da lei Maria da Penha, que é uma legislação protetiva de gênero. ${ }^{7}$

Já o polo ativo, ou seja, o autor do crime, pode ser tanto homem quanto mulher.

O ponto determinante do feminicídio não é o simples ato de matar mulher, mas sim o de matar a mulher em razão dela ser do sexo feminino. As razões condicionantes de sexo feminino são as elencadas no tipo legal, ou seja, o crime cometido por motivação de menosprezo ou discriminação. Segundo Rogério Greco (2017)

\begin{abstract}
"Menosprezo, aqui pode ser entendido no sentido de desprezo, sentimento de aversão, repulsa, repugnância a uma pessoa do sexo feminino; discriminação tem o sentido de tratar de forma diferente, distinguir pelo fato da condição de mulher da vítima".
\end{abstract}

Uma mulher pode ser vítima de homicídio simples, basta não haver a motivação de menosprezo ou discriminação.

Uma ampla pesquisa sobre o feminicídio foi coordenada pela Prof ${ }^{\mathrm{a}}$. Marta Machado, intitulada "A violência doméstica fatal: O problema do feminicídio intimo no Brasil" (2015), esta pesquisa se pauta no mapa da violência de 2012 para ilustrar o alarmante cenário de assassinatos femininos no país. Nesta pesquisa é dito que a violência ocorrida no interior dos domicílios é predominante e que denota uma recorrente vitimização da mulher dentro do espaço doméstico, ocasionada por seus parceiros.

Marta Machado informa em sua pesquisa, que cerca de 50 mil mulheres foram assassinadas entre 2000 e 2010, e relaciona este resultado à violência conjugal.

Em que pese se tratar de realidade lamentável, o mesmo mapa da violência que empresta seus dados estatísticos à pesquisa em comento, traz a seguinte elucidação quanto aos números

7 Segundo o sítio eletrônico MundoPsicologos (2016) sexo é determinado biologicamente, nascemos homem ou mulher. Enquanto que gênero é uma construção psicossocial. 


\begin{abstract}
"Os diversos mapas que vêm sendo elaborados desde 1998 confirmam esse fato. Deles emerge uma constante: a elevada proporção de mortes masculinas nos diversos capítulos da violência letal do país, principalmente quando a causa são os homicídios. Assim, por exemplo, nos últimos dados disponíveis, correspondentes a 2010, dos 49.932 homicídios registrados pelo SIM, 45.617 pertenciam ao sexo masculino $(91,4 \%)$ e 4.27331 ao feminino $(8,6 \%)$. E, historicamente, essas proporções não mudam praticamente de ano um ano para outro."
\end{abstract}

Ou seja, o número de homens vítimas de homicídio, apenas em 2010 representa o número de homicídios de mulheres no período de uma década.

E sobre os locais predominantes de homicídios, segundo o mapa da violência de 2012, $27,1 \%$ dos homicídios femininos ocorreram dentro do ambiente doméstico, contudo 31,2\% dos homicídios tiveram a rua como cenário.

Os dados indicados, tanto de mortes femininas quanto masculinas são alarmantes, e denunciam o grave quadro de violência no Brasil.

\title{
CONCLUSÃO
}

Após uma breve explanação sobre os pontos relevantes das teorias desenvolvidas por Herbert Hart e Joseph Raz; rápidos comentários a respeito do movimento feminista, que gerou pressão social e política, que culminou na edição de várias leis e normas no sentido de proteger a mulher. Além da minuciosa análise do tipo penal do feminicídio, as informações até aqui apresentadas serão processadas e formato de considerações finais.

De início, a análise jurídico-penal, e em seguida, seguirá o confronto entre feminicídio e o sistema de proteção a mulher, segundo as teorias dos autores Herbert Hart e Joseph Raz.

O recente histórico de legislações que conferem a mulher alguns direitos, demonstra uma evidente quebra de isonomia, que se convertem em verdadeiros privilégios.

Quanto ao feminismo, propriamente dito, do ponto de vista normativo, não se sustenta.

O Código Penal prevê pena de 6 a 20 anos de reclusão para aqueles que matarem (ou tentarem) alguém. Esta pena é aumentada no dobro para a mínima, e na metade, para a máxima (12 a 30 anos), para o homicídio qualificado, isto é, homicídios cometidos em circunstâncias diferenciadas, como o emprego de fogo, veneno, tortura, traição, etc.

Uma das qualificadoras do homicídio, é o motivo torpe, nas palavras de Rogerio Greco "Torpe é o motivo abjeto, que causa repugnância, nojo, sensação de repulsa pelo fato praticado pelo agente" (GRECO, p. 480. 2017).

Pode-se considerar que matar uma mulher pelo simples fato dela ser mulher, causa nojo e repugnância, é um motivo torpe.

A futilidade do motivo do cometimento também qualifica o homicídio. 
Logo, se já existe em nosso ordenamento jurídico, norma que pune de forma mais severa, homicídios cometidos dentro de certas circunstâncias, não há razão normativa que justifique a criação de novo tipo penal, que atribui pena já prevista, para ato específico, que perfeitamente poderia ser extraído da norma anterior. Em outras palavras, matar mulher por razão de sexo feminino, já poderia vir a ser punido com a estrutura penal existente.

Há outro fator que desestabiliza a necessidade de existência do tipo penal do feminismo. Sua validade.

A Lei Maria da Penha protege o gênero feminino, e o feminicídio é uma lei que cria proteção ao sexo feminino.

“(...) Não podemos estender tal conceito a outros critérios que não o jurídico, uma vez que, in casu, estamos diante de uma norma peal incriminadora, que deve ser interpretada o mais restritamente possível, evitando-se uma indevida ampliação do seu conteúdo que ofenderia, frontalmente, o principio da legalidade, em sua vertente nullum crime nulla poena sine lege stricta" (GRECO, p. 489, 2017).

Logo o feminicídio não pode seguir o exemplo de sua "irmã mais velha", que ampliou sua proteção para abarcar transexuais.

Outro fator preponderante é o do fato social.

Para justificar a uma proposta de lei, que dará início ao processo legislativo, movimentando o congresso nacional em votações bicamerais e posterior sanção presidencial, deve haver um fato social, político ou jurídico que tenha relevância de tal forma que necessite da alteração do sistema vigente.

Sim, muitas mulheres são mortas, mas muito mais homens são vítimas. Não que se deva buscar uma proteção especial ao sexo masculino, mas que se deve observar o real problema. No brasil não morrem muitas mulheres, no Brasil morre muita gente. Entre elas, mulheres, homens, crianças, idosos etc.

Segundo a professora Marta Machado a criação do tipo penal possui importância no sentido de nomear o fenômeno, denunciar sua existência e chamar a atenção para sua problemática, o estudo do feminicídio "aponta para a importância da disputa ideológica e simbólica sobre gênero no campo da aplicação do direito(...)" (2015, p.66).

De fato, se o objetivo é nomear o problema para destaca-lo, então o Brasil poderia seguir o exemplo do Chile, que assim dispõe

Del Homicidio

ART.390.

El que, conociendo las relaciones que los ligan, mate a su padre, madre o hijo, a cualquier otro de sus ascendientes o descendientes o a quien es o ha sido su cónyuge o su conviviente, será castigado, como parricida, con la 
pena de presidio mayor en su grado máximo a presidio perpetuo calificado. Si la víctima del delito descrito en el inciso precedente es o ha sido la cónyuge o la conviviente de su autor, el delito tendrá el nombre de femicidio.

O Chile apenas nomeia o fenômeno de se matar mulher no contexto familiar de feminicídio, sem tratamento diferenciado.

Dá nome ao problema, não ignora o assunto, e não cria leis sem validade e não produz uma desigualdade contrária àquela que combate.

Superada a análise jurídico-penal do assunto, passamos a análise segundo a teoria do Direito.

Por se tratar de assunto polémico que divide opiniões, que se utilizou a já clássica teoria e Hart, um liberal cujos ideais em muito se assemelham com o discurso padrão feminista; e de Raz, seu aluno, crítico e de certa forma sucessor, que também comunga de ideais liberais.

Desta forma evita-se o argumento de que o aporte teórico utilizado é precipuamente anti-ideológico ao assunto abordado, afinal se referem de dois autores que provavelmente seriam simpáticos à causa.

Inicialmente, convém dizer que o sistema jurídico brasileiro possui problema de identidade, pois busca noções diferentes de justiça no tratamento de mulheres quando comparadas aos demais brasileiros (homens, crianças, idosos, transgenêros).

Para Hart, o sujeito da norma de reconhecimento é a população como um todo (lembrando que a norma de reconhecimento, para Hart, é uma norma que confere poder), já para Raz, a norma de reconhecimento não pode conferir poder e ser para a população, pois a população não possui a obrigação de identificar e diferenciar normas, logo, para Raz, a norma de reconhecimento teria como sujeito as autoridades do Estado, que possuem tal obrigação. São normas que determinam dever de agir, direcionadas às autoridades estatais, mais precisamente aos órgãos com função de julgamento, a agir de determinada forma para cumprir a e fazer cumprir a Lei.

Raz diferencia normas jurídicas de normas não jurídicas pelo princípio da individuação (que enxerga o sistema jurídico como um emaranhado de normas, que por sua vez possui porções destacadas pelo aludido princípio, e estas porções são destacadas para serem aplicadas ao fato em concreto, contudo, apesar de serem utilizadas como uma lei aparentemente independente, por um observador externo, em verdade é parte indissociável de um todo, e exprime a ideia genética do sistema ao qual pertence, ainda que utilizada de forma isolada.

Se apenas as autoridades possuem a obrigação de diferenciar as normas, então o argumento do feminicídio ser mais uma norma para criar propaganda para a causa cai por terra, pois não cabe à sociedade o dever de identificar e diferenciar normas, então a função publicitária de uma lei é, por natureza, completamente incompatível com o sistema jurídico proposto por Raz.

Para Hart, há apenas uma regra de reconhecimento por sistema jurídico. Nesta visão, ou iremos observar a regra de reconhecimento como sendo, obviamente nossa Constituição 
Federal, que pugna pelo princípio da igualdade; ou iremos aceitar que dentro de um sistema jurídico existem subsistemas ou microssistemas, sendo cada um com sua própria regra de reconhecimento. No primeiro caso, tanto a norma primária de conduta do feminicídio, quanto a própria lei Maria da Penha, não passam no teste de validade da norma de reconhecimento, pois ferem de morte o princípio da igualdade (inconstitucionalidade), ao criar enormes abismos de tratamento entre homens e mulheres. O que vai completamente contra a ideia Hartiana de que o comportamento social geraria regras jurídicas com o tempo.

No ponto de vista do microssistema, a regra primária do feminicídio se distancia da sua regra secundária de reconhecimento (lei Maria da Penha) ao quebrar sua lógica de proteção de gênero e passar a proteger apenas o sexo feminino. Em ambos os casos, carece de validade normativa.

O aqui compreendido sistema jurídico de proteção a mulher, na lógica de Hart, já foi completamente descontruído, agora vejamos como se sai diante da teoria raziana.

Raz entende que são os sistemas jurídicos tanto quantos forem os órgãos primários de julgamento, aqui entendidos como o Poder Judiciário.

Aceitando a existência de diversos sistemas jurídicos em paralelo, temos o sistema de proteção à mulher, contudo ao se invocar o princípio da individuação, e se destacando o feminicídio como regra de conduta, não se consegue extrair de seu texto a mesma genética do resto do sistema, o mesmo enunciado fundamental, sendo assim uma regra que não faz parte do sistema, carecendo de identidade.

O critério de identidade de sistema jurídico desenvolvido por Raz "não se limita a apenas fatores jurídicos, mas a outros aspectos sociais, como regimes políticos, religiões etc." (DIAS, PEIXOTO, 2017).

Como um dos objetivos de Raz é auxiliar os profissionais jurídicos a solucionar casos práticos, conclui-se que, dentro do estudo desenvolvido neste trabalho, o objetivo foi alcançado.

Em ambos os casos, sob as óticas de dois jusfilósofos distintos, o Tipo penal do feminicídio não se sustenta, se tratando de aberração jurídica, que apenas infla a legislação brasileira, contradiz sua legislação precedente e causa aquilo que deveria combater. Injustiça.

\section{REFERÊNCIAS}

BITENCOURT, Cezar Roberto. Tratado de Direito Penal, Parte Geral 1. Ed. 15, São Paulo: Saraiva, 2010, p. 31, apud E. Durkhein, Las reglas del métoo sociológico, Espanha, Morata, 1978, p. 83

DIAS, Jean Carlos; PEPEREIRA, Carla Maria Peixoto. A regra de reconhecimento e suas implicações: análise a partir das teorias de Herbert Hart e Joseph Raz. Disponível em: <https://www.conpedi.org.br/publicacoes/pi88duoz/41sqw715/t8QT5H5bODLJUuBF.pdf>. Acesso em : 24 de jan de 2018.

GALVÃO, Agência Pareícia. Dossiê Feminicídio. Disponível em: <http://www.agenciapatriciagalvao.org.br/dossies/feminicidio/pesquisa/mapa-da-violencia- 
2015-homicidio-de-mulheres-no-brasil-flacsoopas-omsonu-mulheresspm-2015/>. Acesso em 9 de jan. de 2018.

GRECO, Rogério. Curso de Direito Penal Parte geral. Niteroi-RJ, Impetus, 15. Ed. 2013.

GRECO, Rogério. Código Penal Comentado. Niteroi-RJ, Impetus, 11. Ed. 2017.

HART, Herbert. O Conceito de Direito. Lisboa: Fundação Callouste Gulbenkian. $3^{\text {a }}$.Ed.

IBPT. Quantidade de normas editadas no brasil. Disponível em: <https://ibpt.com.br/img/uploads/novelty/estudo/2603/QuantidadeDeNormas201628AnosCF. pdf> Acesso em: 27 de dez. de 2017.

ILANUD. A lei de crimes hediondos como instrumento de política criminal. Disponível em <http://www.prsp.mpf.mp.br/prdc/area-de-atuacao/torviolpolsist/RelILANUD.pdf>. Acesso em 04 de jan. de 2018.

IPEA. Avaliando a efetividade da Lei Maria da Penha. Disponível em: <http://www.ipea.gov.br/portal/images/stories/PDFs/TDs/td_2048.pdf >. Acesso em: 4 de jan. de 2018.

MACHADO, Marta Rodrigues de Assis. A Violência Doméstica Fatal: O Problema do Feminicídio Íntimo no Brasil. Disponível em: <http://www.compromissoeatitude.org.br/wpcontent/uploads/2015/04/Cejus_FGV_feminicidi ointimo2015.pdf>. Acesso em 18 de dez de 2017.

MAPA DA VIOLÊNCIA. Os novos padrões da violência homicida no Brasil. Disponível em: 〈http://www.mapadaviolencia.org.br/mapa2012.php>. Acesso em: 03 de jan. de 2018.

MICHAELIS. Burocracia. Disponível em: <http://michaelis.uol.com.br/modernoportugues/busca/portugues-brasileiro/burocracia/>. Acesso em 08 de jan. de 2018.

RAZ, Joseph. $O$ conceito de sistema jurídico: uma introdução à teoria dos sistemas jurídicos. São Paulo: WMF Martins Fontes, 2012.

STOLTZ, Sheila. Um modelo de positivismo jurídico: o pensamento de Herbert Hart. Disponível

em:

<http://bibliotecadigital.fgv.br/ojs/index.php/revdireitogv/article/view/35200/34002>. Acesso em 24 de jan de 2018.

SERRANO, Pedro Estevam. Excesso de leis e imprecisão normativa como mecanismos de exceção. Disponível em: <https://www.cartacapital.com.br/sociedade/excesso-de-leis-eimprecisao-normativa-como-mecanismos-de-excecao>. Acesso em: 27 de dez. de 2017. 